\title{
Teaching Analytical Chemistry to Pharmacy Students: A Combined, Iterative Approach
}

\author{
Jinit Masania, ${ }^{a}$ Martin Grootveld, ${ }^{a}$ and Philippe B. Wilson*,a \\ ${ }^{a}$ Leicester School of Pharmacy, De Montfort University, The Gateway, Leicester, LE1 9BH \\ $5 \quad$ Email: philippe.wilson@dmu.ac.uk
}

\begin{abstract}
Analytical chemistry has often been a difficult subject to teach in a classroom or lecture-based context. Numerous strategies for overcoming the inherently practical-based difficulties have been suggested, each with differing pedagogical theories. Here, we present a combined approach to tackling the problem of teaching analytical chemistry, with particular emphasis on inherently practice-based cohorts such as pharmacists. A composite visual, interactive, didactic and practical approach is presented, in which students are able to fully engage with the teaching/training materials within numerous contexts. From unit evaluations, Student-staff liaison committee feedback and an analysis of marks issued from virtual learning environment quizzes, the enthusiasm of the students for such an approach is found to correlate with their understanding of the topic. The broad outline of the course is included as an example.
\end{abstract} 10

GRAPHICAL ABSTRACT 
1

2

3

4

5

6

7

8

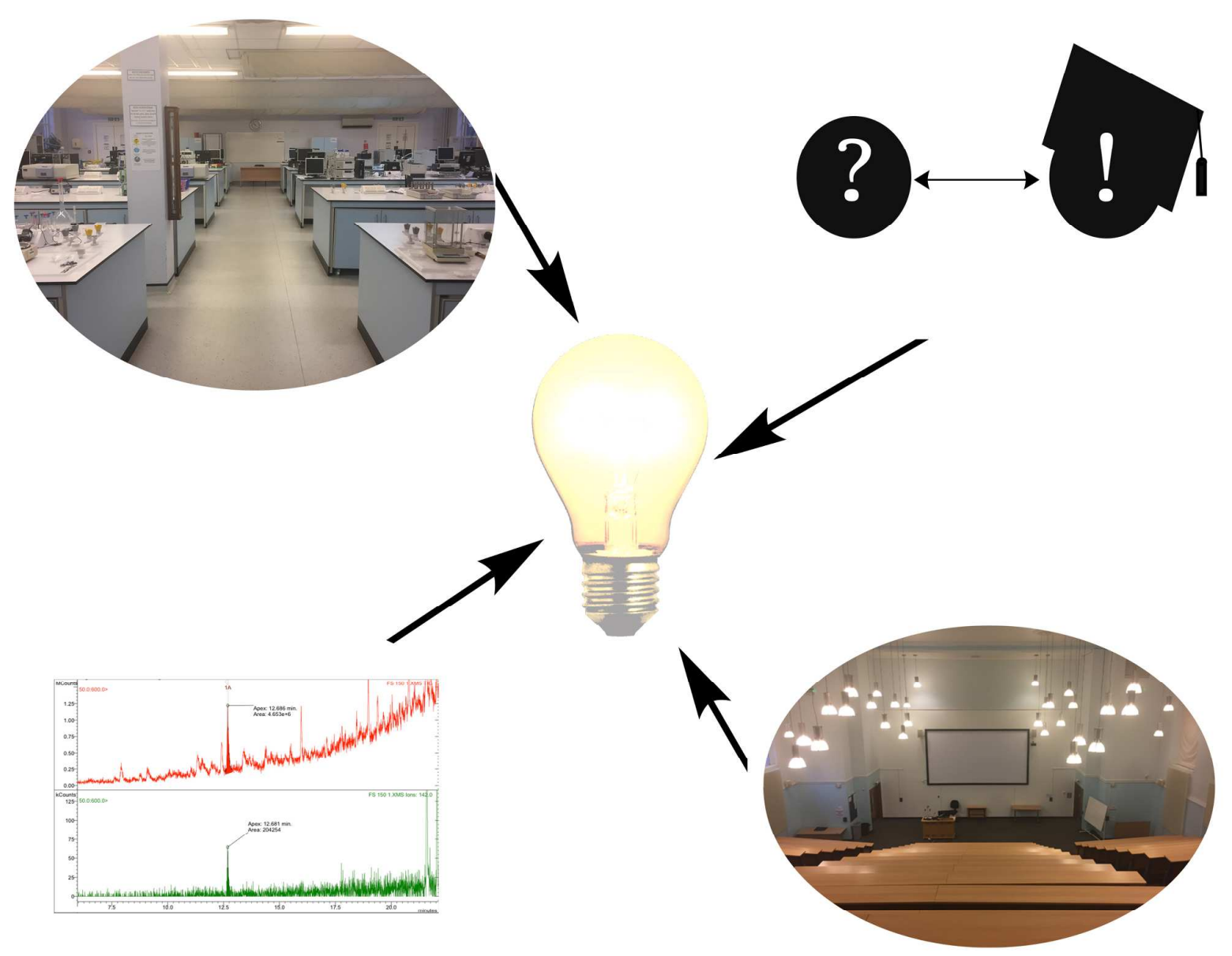


KEYWORDS:

\section{Second-Year Undergraduate, Analytical Chemistry, Collaborative/Co-operative Learning, Hands-On Learning/Manipulatives, Multimedia-Based Learning, Drugs/Pharmaceuticals}

25

\section{INTRODUCTION}

As a subject, analytical chemistry remains a challenging yet vital part of the curriculum ${ }^{1}$, in which students are taught to understand the mechanisms through which analytical techniques function, as well as being expected to interpret and gain quantitative data from a range of methods. It is therefore important that students not only receive this tutelage, but also understand the nature of the techniques considered, and their relative merits and applications. ${ }^{2}$ Indeed, analytical chemistry courses form the foundations of future laboratory work, which is undertaken during the programme of study and beyond. It is therefore of paramount importance that the material is appropriate, and that the students engage sufficiently with the course in order to retain the main points and apply these practically. ${ }^{3}$ Therefore, the major aim of this report is to disseminate these practices towards analytical chemistry teaching, and present student feedback and recorded examination data as supporting supplements for the teaching methodologies used.

In Chemical Manipulation, published in 1827, Faraday described the requirements of a standard laboratory, and informed readers of the importance of chemical apparatus methodology within the skill-set of a self-respecting experimentalist. ${ }^{4}$ It was in this context that Faraday first highlighted the importance of being comfortable with experimental and practical knowledge, in addition to pure theory. Indeed, he paved the way for modern analytical chemistry teaching by encouraging the duality of a course structure, and also developed the interest of the students individually outside the laboratory, before introducing them to the instruments of their future careers. The nature of Faraday's work was also being developed in the America. Scholars had understood the importance of not only teaching respectable experimental methodologies, but also the associated analytical and critical skills; precision and accuracy in chemical testing. Indeed, the authors of an early 20th century US textbook promoted the use of laboratory standard texts and manuals as key pedagogical tools in the understanding of chemical analysis. This went as far as considering the benefits of diagrams as learning aids, concluding that students provided with graphical instructions in combination with text, demonstrated a much improved performance over those limited to text-only manuals. ${ }^{5}$

50 It is now common practice to include a variety of formats in laboratory manuals for ease of use, but also pedagogical benefit. ${ }^{6}$ Diagrams were and still are helpful, particularly regarding equipment set-up, experimental design and analytical procedure. ${ }^{7}$ The use of flow-chart style models has recently been discussed in terms of 
improving understanding and the systematic instructional basis of student cohorts, a format which is readily applicable to an analytical chemistry course. ${ }^{8}$ These flow-charts are often constructed so that they may be repeated multiple times in order to 'entrench' the procedure in the minds of the learning body, thereby encouraging retention of their practical skills. Indeed, a recent study by Grosmark ${ }^{9}$ confirmed that students undertaking additional repetitive practical tasks performed more effectively in experiments subsequently conducted individually, rather than in a generic group exposed to a standard level of technique.

In terms of laboratory supervision and purely practical instruction, a common methodology is referred to as analytical feedback. Classically, the students are observed passively by an instructor who assists by providing tailored advice to them as they go about a practical exercise. ${ }^{10}$ This is then developed by challenging the students with more in-depth work, in which they are encouraged to employ the skills gained in introductory sessions, in a more independent, less inherently supervised setting. Specifically relating to analytical chemistry, to date this has not been formally supported by quantitative research; however, project-style independent courses have proved popular with the student body. ${ }^{11}$ Indeed, the nature of these conditioning or 'carrot-and-stick' strategies have been described by behaviourists in education for many years. ${ }^{12}$ In this approach to learning, students are rewarded or corrected based on their behaviour, with the enforcement of positive behaviour via further reward. Corrections lead to a reduced likelihood of repeated behaviour, whereas the reward of positive behaviour results in a tendency to behave similarly in the future. This method of learning is particularly prevalent in terms of practical studies the subject to be learnt is described initially, followed by a practical demonstration, and finally by the learners repeating the process themselves. Feedback in the context of reinforcement and reward leads to the student appreciating the correct manner of proceeding in the practical worktask. ${ }^{12}$

In addition to providing a medium to learn the theory and practice of analytical techniques, by nature an analytical chemistry laboratory course also concentrates on the mathematical and statistical elements of analysis. ${ }^{13}$ It has been found that setting a significant portion of mark descriptors to skills involved in gauging accuracy and precision leads to more careful work and thought-out manipulations in the students' methodologies. ${ }^{14}$ This is often the major contributing mark to post-laboratory reports, the practical component usually being preceded by an introductory sheet of questions or simply information to alert the students to the task and what is expected of them. Another technique currently showing excellent uptake and receiving positive feedback from learners is the use of videos in practical instruction and a lecture-based context. ${ }^{15}$ Whereas in the late 1990s and early 2000s, CD-ROMs and videodiscs were trialled ${ }^{16}$, the abundance of analytical preparatory and methodological videos on common video sharing websites provide students with another, alternative medium of inquiry. ${ }^{17,18}$ Not only can these video tutorials shorten the introduction for laboratories, but they also provide a change in pace of cohortdelivered material, and have been shown to persist in the understanding loop for up to 24 hours when instructionbased. ${ }^{19}$ 
In terms of an entire module, as is often the case in analytical chemistry undergraduate programme structures, the importance of "why to how" connection is evident. Indeed, providing lecture-based material which is then built upon in different settings provides learners of all categories with the opportunity to engage with the syllabus, as well as reiterating similar information in multiple settings, and thereby incorporating the repetitive element described above..$^{20}$ The combined course described herein includes elements from these pedagogical strategies, together with novel and more progressive reasoning from recent years.

Herein is presented a combined analytical chemistry lecture and practice-based course, delivered to cohorts of 110 students of mixed ability, and predominantly from a diverse ethnic background. The majority of students follow the common course from advanced level secondary education through to university, with a minority being mature students and those from professional backgrounds. This course is delivered in the second year of a Pharmacy programme, and builds upon basic analytical science presented to the students in the first year. Students already have exposure to simple techniques such as IR and titration experiments, but have yet to undertake a dedicated analytical topic within a module. The subject is presented with a more defined practice-based approach, where each technique is intrinsically linked to its pharmacological or pharmaceutical uses, with quantitative and qualitative examples provided. Throughout the discussion, the term module is used to refer to a particular collection of related topics, grouped together to form part of a credited, stand-alone unit of assessment. The module referred to in the context of this course is valued at 30 credits out of the 120 for the year two total, of which $25 \%$ of this is attributed to the analytical portion.

The students follow the course across the second semester of the year, having had basic training in analytical mathematics from an 'in-house' service at De Montfort University, Leicester, which offers free mathematics tutorials to students. 12 lectures are delivered to the students, with intermediate tutorials and laboratory classes alternating (Figure 1). Lectures are time-tabled for one hour periods, as indeed are tutorials. Laboratory classes have a duration of four hours; exercises and pre- and post-laboratory tasks can be easily completed within this time-frame.

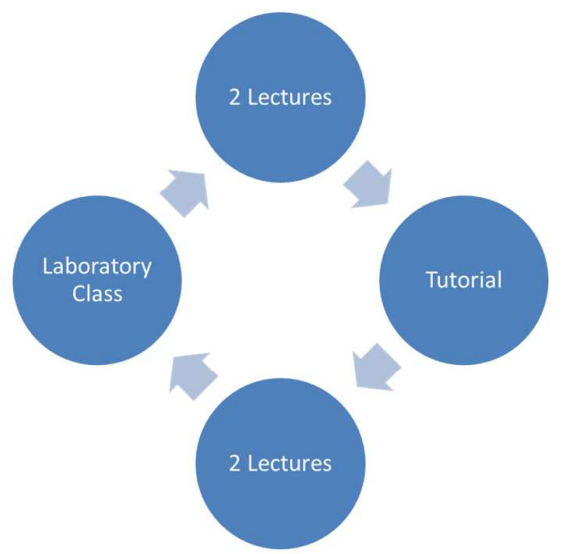


Figure 1. Analytical Chemistry course cycle through which students begin with two lectures, followed by a tutorial and two additional lectures before participating in the associated 4 hour laboratory class.

The carousel depicted in Figure 1 is repeated three times in order to encompass the 12 lectures, three laboratory classes and tutorials. The lectures are designed to build upon each technique, giving the cohort a wide perspective on available analysis methodologies and their applicability to the work they are performing and current research being undertaken. The cycles and progression of subjects is described in Table 1. The students begin with a series of lectures on UV/Vis spectrophotometry and Fluorescence spectroscopy, where the ideas from electronic absorption spectroscopy are developed into the emission theory of the fluorescence component of the course. Each lecture is similarly formatted, giving the students a uniform field in which to learn the basics, theory, and advantages/disadvantages of each technique. They are first guided through the basic theory of each method, where they are presented with the advantages and disadvantages of the technique as a summary. In addition to this, following the presentation of the basic analytical methodology, each technique features a well-documented video of 2-6 minute duration, which contains animations/diagrammatic representations to facilitate the learning process. Indeed, numerous sources have highlighted the merits of employing videos/animations as a pedagogical tool, ${ }^{21}$ and this is particularly pertinent to the field of analytical chemistry, where videos and animations provide the students with an additional viewpoint and information which is inherently difficult to transfer through powerpoint slides. ${ }^{22}$ These short videos serve the purpose of discussing key concepts in bite-size sections, and in combination with the practical demonstration videos, offer an entirely new perspective on the analytical techniques being studied.

The lectures build upon the basic theory to explore spectral profiles and data obtained from the application of each technique and/or method involved. This is not only referred back to relevant examples, but data obtained is also analysed with respect to its validity and applicability. Additional details of selected lecture content are included in the Supplementary Information. The benefits and drawbacks associated with each method are therefore reinforced through this process, these first being introduced in the advantages/disadvantages section of each lecture. Each lecture features an element of student participation, a process which has been shown to break up the monotony of traditional academic-led lecture styles, and also invigorate student cohorts. Indeed, students engaging in so-called active learning have been shown to exhibit greater subject retention than those engaged in passively oriented classes. ${ }^{23}$ During this lecture series, students were requested to contribute with clicker style exercises to questions, as well as live demonstrations. These often took the form of props, which students would use to illustrate concepts. For the mass spectrometry lecture element, volunteer students used foam dart guns to shoot high energy 
electron moieties onto a large supramolecule created with the Orbit molecular building system. They thought of the darts as electrons, and after removing sections, were able to reconstruct this and hence deduce the molecular structure.

Tutorial sessions take place after the initial two lectures in each cycle, most especially to allow the students to have dedicated time with the academic teaching the topic. The cohort of 110 was split into 5 groups of 22, and each were scheduled individually with the academic leading the lecture course on this topic, and there were opportunities for the students to ask questions and engage with the ideas in a quieter context. The tutorials for techniques that were to be used in the laboratories featured question sheets and tasks to complete in the session and a talk through with the academic involved. This gave students the onus to complete their understanding of the ideas presented in the lectures. Tutorials on the more advanced analytical techniques featured demonstrations in the small groups on the relevant equipment or facilities featured. For example, students in their groups of 22 spent some time in the mass spectrometry laboratory, being shown the pathway from unknown sample to characterisation. They asked questions and had the opportunity to discuss the relative merits and applications of the technique with the senior technician in charge of the facility.

The ideas raised in the lectures and tutorials were then put into practice in the labotatory classes during the final laboratory element of each cycle. Here, the students were provided with exercises in each of the techniques described in Table 1. Each technique is designed to build upon the ideas and theory described in lectures, all the time providing conceptual relevance to the field of Pharmacy, via exercises involving the characterisation and analysis of drugs and unknown samples.

Table 1. Description of Techniques Addressed within the Three Course Cycles

\begin{tabular}{|c|c|c|c|c|c|}
\hline \multirow{2}{*}{$\begin{array}{l}\text { Course } \\
\text { Cycle }^{a}\end{array}$} & \multirow{2}{*}{$\begin{array}{c}\text { Lectures } \\
1 \text { and } 2\end{array}$} & \multirow[t]{2}{*}{ Tutorial } & \multirow[t]{2}{*}{ Lectures 3 and 4} & \multicolumn{2}{|c|}{ Lab Class } \\
\hline & & & & Group 1 & Group 2 \\
\hline 1 & IR & IR; UV-vis; Fluorescence & UV-vis, Fluorescence & IR & UV-vis, Fluorescence \\
\hline 2 & HPLC & HPLC; GC & GC & HPLC $b$ & $\mathrm{GC}^{b}$ \\
\hline 3 & NMR & NMR; MS & MS & UV-vis, Fluorescence & IR \\
\hline \multicolumn{6}{|c|}{$\begin{array}{l}\text { aThe entire cohort attends each session: it is only in the laboratory that they are split into groups in order to } \\
\text { make effective use of the equipment available. bAll students had the opportunity to work with chromatographic } \\
\text { equipment, either gas or HPLC. Students using the chromatographic equipment were split into two parts within } \\
\text { the groups; half used the GC, half used the HPLC. Upon completion, students formulated a joint HPLC and GC } \\
\text { report, which contained information from both groups. A similar strategy is used for NMR and MS. }\end{array}$} \\
\hline
\end{tabular}




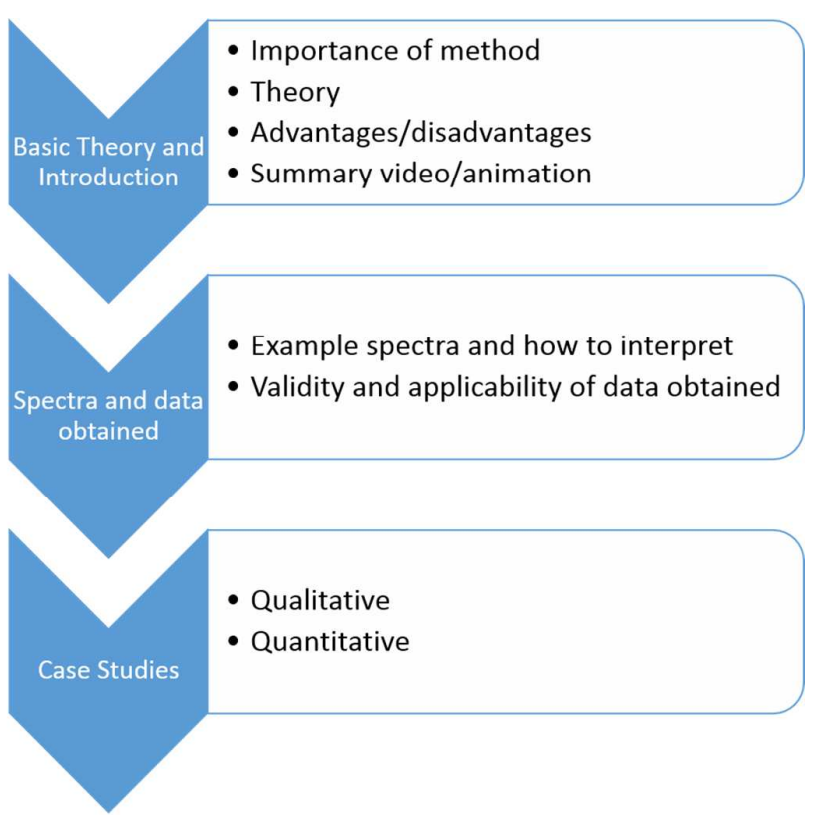

Figure 2. Basic structure for each lecture of the analytical phase of the module. Lectures are split into three broad sections, providing a template that students can follow throughout each topic. The lectures begin with a basic introduction to the theory associated with the analytical technique, which is then followed by some examples of data output from application of the technique featured to simple analytes. Case studies complete each lecture, where an entire experimental methodology is described from beginning to end, and which highlights both the qualitative and/or quantitative nature and analytical advantages of each technique.

Titsworth and Kiewra briefly discussed the importance of uniformity in lecture style in learning and retention from a student perspective. ${ }^{24}$ Indeed, numerous studies have shown that maintaining a consistent approach to presenting information enables the students to subconsciously retain particularly relevant and important points. ${ }^{25}$ Once the basic information and data interpretation sections have been discussed, students are presented with at least two case studies, showcasing the relevance of the particular analytical technique to the programme of study. These case studies consist of at least one quantitative and one qualitative element, which describe to the students the multipolar approach available to them with each technique (Figure 2).

The subject of mathematical application to analytical science has often been discussed in terms of pedagogy. ${ }^{26}$ Indeed, there are studies which support the idea of particularly emphasising quantitative skills in a tutorial-based 
context, ${ }^{27}$ together with those suggesting that personal solitary work shows greater rates of success. ${ }^{28}$ Within the remit of this course, students are expected to develop sufficient skills to understand the theory behind the methods available to them, but also to confidently apply analytical methodologies to the analysis of data acquired and draw reasonable conclusions from these. This provides an important step in their developments as scientists, and as such requires much consideration in terms of a pedagogical approach.

A combined attitude was undertaken regarding teaching the quantitative skills necessary to being a competent analyst. Indeed, students are presented with the quantitative basis of each of the techniques in the lecture, and a case study highlights the applicability to pharmaceutical analysis. In turn, the first tutorial of the series, which appears after the original electronic spectroscopy component, consists of a thorough intermediate session of statistical analysis and interpretation for scientific analysis, and operated by trained mathematicians. The cohort of 110 is split into 5 equivalent groups, of 22. Each group benefits from a 1:22 session with a trained mathematician who guides the students through scientific analysis and basic statistics. This then provides the cohort with a solid grounding to developing these ideas and skills during the lectures, laboratories and subsequent tutorials. Simple skills such as dilution factors and understanding the equation for a linear regression relationship, serve to facilitate the learning of concepts that they will encounter later in the course.

\section{RESEARCH METHODS}

The aim of this work was to offer a balanced perspective on the practice of teaching analytical chemistry in the context of an undergraduate MPharm pharmacy course, providing educators in other institutions with examples of a system that has already generated positive student feedback. The feedback is used to inform the course design, and selected student grades provide an alternate perspective to the nature of teaching of the course. The main purpose of obtaining student feedback has often been regarded as a means of enhancing their experience of learning and teaching. Indeed, this can also be extended to the monitoring of standards of teaching and ensuring high quality learning experiences for the cohorts involved. Feedback can also highlight good practice, contribute to staff development, and facilitate dialogue with students. The feedback obtained throughout the course of this work pertains only to students undertaking this module and therefore the topic concerned.

Students provided feedback 'in class', which was recorded at the mid-point of the lecture series on analytical chemistry through a stop-start-continue exercise. This allowed for mid-point feedback to be put into action during the second half of the teaching module involved, and prior to its completion within the module. 
Stop-start-continue feedback was obtained through the standard methodology ${ }^{29}$ Students were provided with a post-it note, where they wrote "stop", "start", and "continue" on individual lines. They then proceeded to detail the aspects of the teaching they wished to cease (stop), any practice which they would like to see implemented (start), and examples of good practice they wished to see carry through to the end of the topic within the module (continue). Feedback was taken at the end of the lecture midway through the topic, and students were requested to not limit their opinions to lectures, but to extend this to tutorials and laboratory classes also. The feedback was collected with an open-ended method, and this allowed students to describe their feelings relating to the teaching and material within this topic of the course. In the interest of clarity, broadly similar comments were regrouped into the themes described in Table 2.

\section{Statistical Analysis}

Linear and polynomial regression statistics were performed using the XLSTAT2016 software module option. This software was also employed to perform one-way analysis-of-variance (ANOVA) in order to determine the significance of any differences in mean mark values between groups featuring increasing numbers of students (22) within tutorial groups. However, it was found that the intra-group variances $\left(\mathrm{s}_{\mathrm{i}}^{2}\right)$ significantly differed between groups (i.e., they were heteroscedastic); this was confirmed by highly significant Bartlett's and Levine's test statistics (p values $2.90 \times 10^{-3}$ and $3.60 \times 10^{-4}$ respectively). Therefore, we employed the Welch ANOVA and Brown-Forsythe F ratio test models rather than standard ANOVA, since these approaches have no requirement for the homoscedasticity assumption when performing ANOVA evaluations. Prior attempts to homogenise these intra-group variance values, including $\log _{10^{-}}$, square root and cube root transformations, were unsuccessful.

\section{RESULTS AND DISCUSSION}

Conceivably, a study of this type could ask questions such as "to what level has the teaching in this topic positively affected the students' performance on this module"? Or alternatively "what was the level of student satisfaction for this model of teaching analytical chemistry?". Both questions can be answered by similar data obtained from the student body. Indeed, data from both the cohort themselves (in the form of the stop-startcontinue feedback), in addition to examination data can provide the basis for analysis of these methods used in analytical chemistry teaching at an undergraduate level.

As discussed above, and with reference to the literature, ${ }^{26-28}$ mathematical skills form an integral part of analytical chemistry, and represent the backbone of a successful analytical pathway. Therefore, the student cohort was offered the opportunity to spend some time with an internal mathematics expert from the institution mathematics help centre; more and more higher education providers are now investing in this resource for their student bodies. The uptake for these tutorials was indeed significant, with a final register attendance of $96 \%$ upon completion of the final session, with average marks for practical and online assessments shown in Figure 3. Feedback from these 
sessions was very positive, with students commenting that they could apply the topic to more than simply this lecture course and topic, but to other components of the MPharm pharmacy programme.

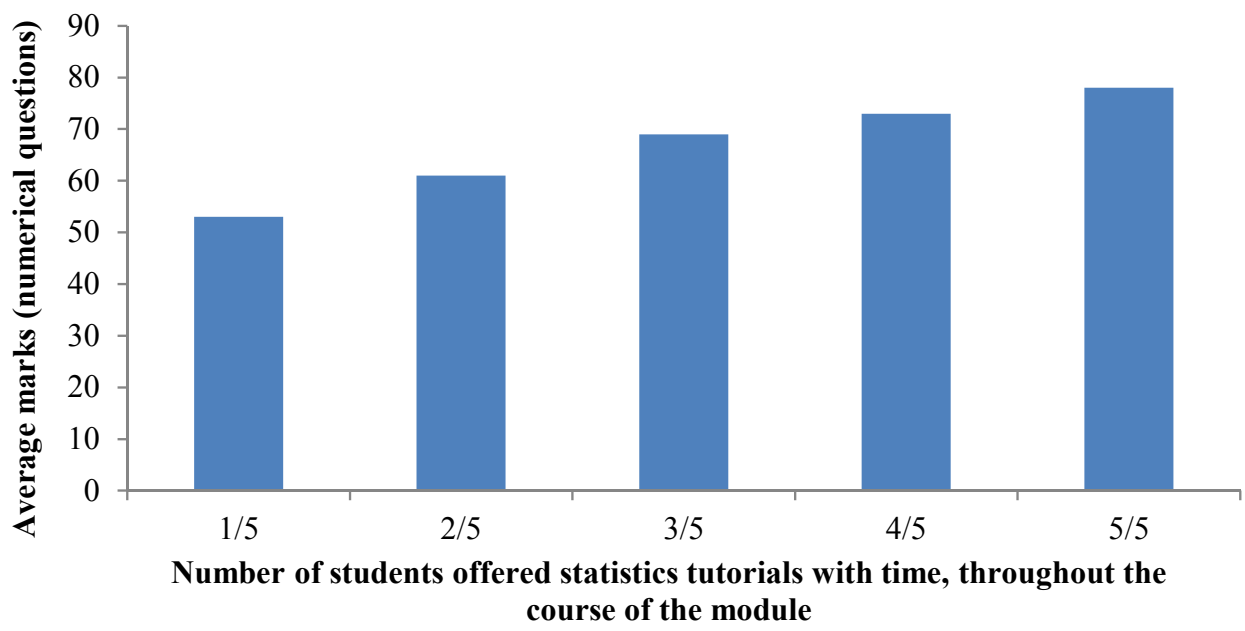

Figure 3. Mean marks for numerical questions in practical classes over the total number of students having been offered tutorials. Available marks range from $0-100$.

A very highly significant simple linear relationship was observed between the scores for numerical questions in online self-assessments, and students offered statistics tutorials $\left(p<10^{-8}\right)$; no evidence for a higher order polynomial (i.e., quadratic) relationship between these variables was obtained. Analysis of variance (ANOVA) indicated very highly significant differences between mark responses and students having been offered tutorials in statistics methods ( $p=2.56 \times 10^{-8}$ and $1.65 \times 10^{-6}$ for the Brown-Forsythe $\mathrm{F}$ ratio and Welch ANOVA statistics respectively). Further post-hoc analysis using Tukey's highest significant difference (hsd) test showed statistically-significant differences between mean marks awarded and the cumulative total of students in each group. An overview of the complete statistical analyses of the mark dataset is included in the Supplementary Information.

Intriguingly, a plot of the standard deviations of student number group marks versus mean mark values provided strong evidence for an inverse, relationship between these two parameters (Figure 4), i.e. the 'scatter' of the mark values was found to significantly decrease with the magnitude of the mean mark parameter. Moreover, there was some evidence for a quadratic decrease in this value throughout the mean mark range explored ( $\mathrm{R}^{2}$ increased from a value of 0.9822 to 0.9944 following the inclusion of a squared mean mark function in the regression equation). Although in laboratory experiments featuring analytical chemistry determinations, it is well known that the 
experimental error, usually reflected as a standard deviation or variance estimate, usually increases with the magnitude of the value (e.g., concentration variable) monitored, such a relationship will not necessarily apply with respect to marks attained by students in assessment tests, especially the investigation documented here which has an experimental design comprising the exposure of increasing numbers of MPharm students to focused tutorials. Indeed, this may be rationalised by the improvement of a significant number of potentially weaker and/or less informed students following exposure to these tutorial sessions, but not so for those who were stronger and/or more fully informed. If this was the case, a decreasing level of mark distribution scatter or variance with increasing numbers of tutorial-incorporated students may be expected, although the ceiling of $100 \%$ will also serve to constrain such variance values. This may be rationalised by a consideration of relative contributions of students to their final mark outputs during this trial.

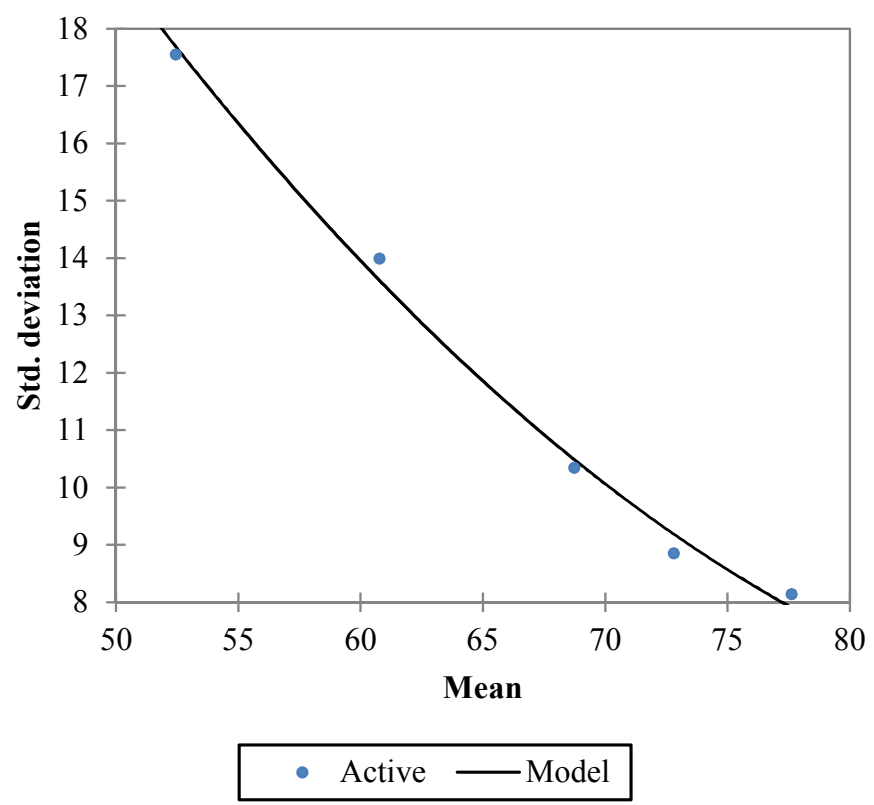

Figure 4. Non-linear regression plot, showing the decrease in standard deviation of marks for each group, with mean, where the range of possible scores is from $0-100$.

The average marks for the numerical portions of self-assessments performed by the cohort on the online virtual learning environment (VLE) used by the institution increased with the number of tutorial classes held. In view of the high attendance, this can be attributed to familiarity with the material, and also confidence in applying the 
theories discussed with the session leaders. This session had not been offered in previous years of this module operating, and therefore examination questions with mathematics components tended to be answered poorly, or not at all. This is particularly distressing, since confidence in mathematics is vital for practicing pharmacists in drug delivery and prescribing. Unlike previous years, more than half the cohort $(n=61)$ attempted the mathematically-based questions in the final section of the examination. Moreover, more than $60 \%$ of these achieved first class grades (i.e. $>70 \%$ mark level) in the questions with mathematical elements. This suggests that dedicated time spent on statistics and mathematics in tutorial environments not only increases the understanding of the student body, but also the confidence to answer these respective questions. Since these skills were refreshed/taught to develop the students, they are found to perform better in numerically-based questions from the practical components and self-assessment tests online. This suggests that organising the mathematics tutorials early on is an excellent procedure to prepare the students for the remainder of the course.

Table 2. Comparative Pharmacy Student Stop-Start-Continue Feedback Responses for the Teaching and Learning Methods Used in the Analytical Chemistry Second-Year Module Topics

Feedback Categorized into These Comment Areas $^{a}$

Inventive teaching strategies

Structure of lectures and notes

Movement of academic during lecture

Animations to explain concepts

Self-study questions
Students' In-Class Reactions, \% $(N=74)^{b}$ Stop

0
Start

0

0

0

10

2

\section{Continue}

36

57

10

20

12

$a$ Feedback reflects comments broadly grouped into the five comment areas described above. $b$ Of the total cohort $(N=110), 74$ students opted to participate, yielding a response rate of $67 \%$.

A total of 89 students were present at the session where stop start continue feedback was obtained. Of these, 74 participated in the stop-start continue exercise, or $67 \%$ of the cohort $(n=110)$. This is a reasonable sample size ; it has often been pointed out that student response rates for surveys and feedback are notably low. ${ }^{30}$ Indeed, higher education institutions often report feedback rates of $20-40 \%$, prompting questions as to the validity of conclusions drawn from such data. ${ }^{31}$

The continue feedback in Table 2 suggests that the students respond positively to a number of the teaching and learning strategies used during the course of the lectures. Indeed, a large proportion of the participants appreciated 
the uniformity and structure of the slides and handouts, and the fact that these were printed out and provided to them. Additional comments were made that this facilitated understanding by listening to the academic and engaging with the material, rather than concentrating on noting all the points verbatim, as some students do. Indeed, a number of studies have shown that providing lecture notes has a tendency to promote less passive learning from a cohort, and encourages them to engage with the material more extensively so than that noted with simple transcription of notes. ${ }^{32}$

The cohort appreciated the use of inventive teaching strategies, with $36 \%$ of responses featuring this theme. This included comments such as allowing students to see more advanced equipment in the tutorials (such as Mass Spectrometers), and innovation in active learning strategies (props, student volunteers). The positive comments about the movement of the academic during the lectures were somewhat mitigated by the negative feedback, with $10 \%$ of students responding positively to the academic walking while delivering the material, and $7 \%$ commenting on this in the Stop feedback. Animations featured positively in the feedback, although students requested more of these for the more complex concepts.

The cohort appreciated the incorporation of self-test questions in the VLE, with $12 \%$ of positive comments; $2 \%$ requested this feature. It is likely that this $2 \%$ were not aware of the availability of the material, and therefore a slide showing the path to the VLE site was appended to each lecture, highlighting the various additional learning tools available. Positive uptake was observed as visitors to the VLE sub-site, and additional questions increased from $68 \%$ of the cohort to more than $90 \%$ once the online address and location had been included in the final slide of each lecture past the mid-point feedback session.

\section{CONCLUSIONS}

Herein, the approach of a combined solution to analytical chemistry teaching has been described. By pooling novel and well-established pedagogical techniques to a course where the practical and theoretical components are intrinsically interlinked, the students have shown an excellent response, both academically and pastorally through feedback. The basic layout of each lecture and the carousel-style organisation of the course provided the students with a solid grounding in analytical mathematics, whilst demonstrating inter-relation with practice. Their analytical practical skills are developed through an established laboratory course, and more advanced methods are introduced to them in smaller-group tutorials, exposing the student practically to each of the methods discussed theoretically in the interactive lectures. Lectures were split into tradition didactic portions, with animation/video sections for techniques, and interactive student participation for each method discussed. Such a multifaceted approach has been shown to lead to an advanced retention of the information described, which is especially ascribable to visual, and stimulating cues from the sessions. 
The benefits of dedicated statistical and mathematical support have been clearly demonstrated in terms of selfassessment exercise grades and student feedback. Support from the student cohort was observed from the incorporation of modern learning technologies and more active teaching and learning approaches. The original approaches of Faraday and his contemporaries ${ }^{4,5}$ regarding the linking of theory to experiment have been developed over a number of years, with the work presented here being an example of working practice. Arguably, it is relatively simple for analytical chemistry courses to concentrate on particular areas individually, without providing any significant linkages between the topics discussed and presented to the students. However, the strategy presented here, and those of others, have shown the benefits of a so-called combined approach, where a logical progression of techniques, experimental practice and theory are developed, allowing the students to discover the links themselves and forging their own understanding of the topics within the module. ${ }^{6-9}$

Indeed, the merits of theories behind individual components of this course have been discussed in detail elsewhere; however it is important for the whole to be applied as opposed to segmented pedagogical activities. Swenson and Lents suggest that the use of virtual learning environments and virtual tutorials can improve the understanding of a student group. ${ }^{1}$ This has advantages in terms of time constraints for the staff teaching the module, however does not include the individual contact time some student groups and groups of learners need in order to process and digest information.

Roche has discussed the merits of relating core theoretical concepts, such as structure activity relationships, to inherently practical and clinical practices of pharmacists, thereby providing context, and often initiative for the students to lead in their own learning. ${ }^{3}$ Similar ideas have been applied to the course described in the current work, using research-based case studies in the lectures, tutorials and laboratory exercises to provide a link to current work being carried out in the field.

Benedict and Pence ${ }^{18}$ have highlighted the incorporation of student-led teaching through modern learning technologies such as smartphones. Indeed, we have shown that students engage more actively with material when presented in different manners, such as employing in-class quizzes. There remains however the concern of smartphone availability for such practices. Moreover, some groups of students would be presented with difficulties if these were the only options of accessing material. It is widely known that most student groups in top-tier US and EU institutions will likely have access to smartphone technology, however this presents difficulties to more disadvantaged groups and locations. One common alternative, as used in the course of this research, is clickers. Clickers are provided to the class and retrieved at the end of the session, allowing all students to engage individually with the questions presented in the lecture. Furthermore, the use of clickers has proven advantages over smartphones, owing to the range of distractions associated with personal electronics. ${ }^{33}$ 
Student feedback for this module was very encouraging, and also highlighted the overall positive nature of the comments made by the cohort. Changes were incorporated into the delivery of the course following the mid-point feedback in the form of increased visibility of concept animations and self-test exercises, together with additional tutorial videos explaining more advanced concepts, as well as making additional resources available through online repositories. ${ }^{34}$ The academic administering the analytical topic within the module either created these tutorial videos, or suitable references materials from online video repositories were included. A uniformly positive range of feedback was obtained from the cohort, suggesting that these teaching and learning methods were successful in engaging the student body as a whole.

It is therefore recommended that this combined approach be considered for courses with significant theory/practice overlap, in which the cohort is able to engage with each component individually, and also relate these topics together.

\section{ASSOCIATED CONTENT}

Supporting Information

Supporting Information is available on the ACS Publications website at DOI:

Statistical analyses for the self-assessments: regression of marks by student number, predicted marks and quadratic fitting, including standardised coefficients.

\section{AUTHOR INFORMATION}

Corresponding Author

*E-mail: philippe.wilson@dmu.ac.uk

\section{ACKNOWLEDGEMENTS}

P.B.W. wishes to thank Richard Brawn, and Kim Fisher for helpful discussions.

\section{NOTES AND REFERENCES}

1. He, Y.; Swenson, S.; Lents, N. Online video tutorials increase learning of difficult concepts in an undergraduate analytical chemistry course. J. Chem. Educ. 2012, 89, 1128-1132.

16 
2. Jolley, D. F.; Wilson, S. R.; Kelso, C.; O'Brien, G.; Mason, C. E. Analytical Thinking, Analytical Action: Using Prelab Video Demonstrations and e-Quizzes To Improve Undergraduate Preparedness for Analytical Chemistry Practical Classes. J. Chem. Educ. 2016, 93, 1855-1862.

3. Roche, V. F.; Alsharif, N. Z. Staying Alive. Advancing Medicinal Chemistry by Enhancing Student Responsibility for Learning. Am. J. Pharm. Educ. 2002, 66, 319-328.

4. Faraday, M. Chemical Manipulation; W. Phillips: London, 1827.

5. Smith, A.; Hall, E. H. The Teaching of Chemistry and Physics in the Secondary School; Longmans, Green, and Company: New York, 1902.

6. Ma, X. F.; Sun, R.; Cheng, J. H.; Liu, J. Y.; Gou, F.; Xiang H. F.; Zhou, X. G. Fluorescence AggregationCaused Quenching versus Aggregation-Induced Emission: A Visual Teaching Technology for Undergraduate Chemistry Students. J. Chem. Educ. 2016, 93, 345-350.

7. Maor, D. University Lecturers as a Community of Learners: A Journey Between Pedagogy and Technology. In Proceedings of ED-MEDIA 2004-World Conference on Educational Multimedia, Hypermedia \& Telecommunications, Cantoni, L., McLoughlin, C., Eds.; Association for the Advancement of Computing in Education: Waynesville, NC, 2004; pp 3642-3649. https:/www.learntechlib.org/p/12040/ (accessed Oct 2017).

8. Giordano, D., Maiorana, F. Use of cutting edge educational tools for an initial programming course. In Proceedings of the 2014 IEEE Global Engineering Education Conference (EDUCON), Istanbul, Turkey, 2014; Institute of Electrical and Electronics Engineers: Piscataway, New Jersey, 2014; DOI: 10.1109/EDUCON.2014.6826147.

9. DeMeo, S. Teaching Chemical Technique: A Review of the Literature. J. Chem. Educ. 2001, 78, 373-379.

10. Miloslavsky, E. M.; Boyer, D.; Winn, A. S.; Stafford D. E. J.; McSparron, J. I. Fellows as Teachers: Raising the Educational Bar. Ann. Am. Thorac. Soc. 2016, 13, 465-468.

11. Krause, S. J.; Baker, D. R.; Carberry, A. R.; Koretsky, M.; Brooks, B. J.; Gilbuena, D.; Waters, C.; Ankeny, C. J. Muddiest Point Formative Feedback in Core Materials Classes with YouTube, Blackboard, Class Warm-ups and Word Clouds. In Proceedings of the 120th ASEE Annual Conference and Exposition, Atlanta, GA, Jun 23-26, 2013. https://peer.asee.org/22301 (accessed Oct 2017).

12. Thorndike, E. L. Educational psychology: The psychology of learning; Teachers College Press: New York, 1913. 
13. Chernova, R. K.; Kulapina, E. G. On the Teaching of Analytical Chemistry at the Chemistry Department of Saratov State University. J. Anal. Chem. 2003, 58, 892-894.

14. Salter, C. ANAPOGIL: Strategies for teaching statistics in the context of analytical chemistry. Abstracts of Papers of the American Chemical Society, 236th ACS National Meeting of the American Chemical Society, Philadelphia, PA, Aug 17-21, 2008; American Chemical Society: Washington, DC, 2008; CHED 334. http://oasys2.confex.com/acs/236nm/techprogram/P1206496.HTM (accessed Oct 2017).

15. Gulinska, H. Using New Technologies in Teaching Chemistry In Chemistry Education in the ICT Age; Gupta Bhowon, M., Jhaumeer Laulloo, S., Li Kam Wah, H., Ramasami, P., Eds.; Springer: Netherlands, 2009; pp 131144.

16. Barek, J. Use of Video Programs in the Teaching of Analytical Chemistry. Chem. Listy. 1995, 89, 399-400.

17. Lichter, J. Using YouTube as a Platform for Teaching and Learning Solubility Rules. J. Chem. Educ. 2012, 89, 1133-1137.

18. Benedict, L.; Pence, H. E. Teaching chemistry using student-created videos and photo blogs accessed with smartphones and two-dimensional barcodes. J. Chem. Educ. 2012, 89, 492-496.

19. Ferris, C.; Alcudia, A.; de Paz, V. Implementations of New Teaching Methodologies To Promote the Participation of Students: Application of Collaborative Blog-Based Learning Techniques. In Proceedings of the 3rd International Conference on Education and New Learning Technologies, Barcelona, Spain, Jul 4-6, 2011; International Academy of Technology, Education and Development: Valencia, Spain, 2011; pp 2995-3000. https://ibrary.iated.org/view/FERRIS2011IMP (accessed Oct 2017).

20. Teo, T. W.; Tan, K. C. D.; Yan, Y. K.; Teo Y. C.; Yeo L. W. How flip teaching supports undergraduate chemistry laboratory learning. Chem. Educ. Res. Pract. 2014, 15, 550-567.

21. Kraft, A.; Rankin, E. S.; Arrighi, V. Using Short Videos To Supplement Lectures on Reaction Mechanisms, Organic Spectroscopy, and Polymer Chemistry In Advances in Teaching Organic Chemistry; Duffy-Matzner, J. L.; Pacheco, K. A. O., Eds.; ACS Symposium Series, American Chemical Society: Washington DC. 2012; pp 209-224.

22. Chasteen, T. G. Web-Based Animation in Analytical Chemistry In Active Learning: Models from the Analytical Sciences; Mabrouk, P. A., Ed.; ACS Symposium Series, American Chemical Society: Washington DC 2007; pp 123-139.

23. Gauci, S. A.; Dantas, A. M.; Williams, D. A.; Kemm, R. E. Promoting student-centered active learning in lectures with a personal response system. Adv. Physiol. Educ. 2009, 33, 60-71. 
24. Titsworth, B. S.; Kiewra, K. A. Spoken organizational lecture cues and student notetaking as facilitators of student learning. Contemp. Educ. Psychol. 2004, 29, 447-461.

25. Ali, F. R.; Hassan, F.; Hasan, S. M. F.; Israr, F.; Shafiq, Y.; Arshad, H. M. Perception and attitude of Pharmacy students towards learning tools. Pak. J. Pharm. Sci. 2015, 28, 2185-2189.

26. Salzer, R. Eurocurriculum II for Analytical Chemistry approved by the Division of Analytical Chemistry of FECS. Anal. Bioanal. Chem. 2004, 378, 28-32.

27. Allen, P. J.; Baughman, F. D. Active Learning in Research Methods Classes Is Associated with Higher Knowledge and Confidence, Though not Evaluations or Satisfaction. Front. Psychol. 2016, 7, 279.

28. Velasco, J. B.; Knedeisen, A.; Xue, D. H.; Vickrey, T. L.; Abebe, M.; Stains, M. Characterizing Instructional Practices in the Laboratory: The Laboratory Observation Protocol for Undergraduate STEM. J. Chem. Educ. 2016, 93, 1191-1203.

29. Hoon, A.; Oliver, E.; Szpakowska, K; Newton, P. Use of the 'Stop, Start, Continue' method is associated with the production of constructive qualitative feedback by students in higher education. Assess. Eval. High. Educ. 2015, 40(5), 755-767.

30. Weaver, M. R. Do students value feedback? Student perceptions of tutors' written responses. Assess. Eval. High. Educ. 2006, 31, 379-394.

31. Sax, L.J.; Gilmartin, S.K.; Bryant, A.N. Assessing Response Rates And Nonresponse Bias In Web And Paper Surveys. Res. High. Educ. 2003, 44, 409-432.

32. Ritter, M. E.; Lemke, K. A. Addressing the "Seven Principles for Good Practice in Undergraduate Education" with Internet Enhanced Education. J. Geogr. High. Educ. 2000, 24, 100-108

33. Bojinova, E. D.; Oigara, J. N. Teaching and Learning with Clickers: Are Clickers Good for Students? Interdiscipl. J. E-learn. Learn. Objects. 2011, 7, 169-184.

34. Williams, I. H.; Wilson, P. B. SULISO: The Bath suite of vibrational characterization and isotope effect calculation software. Software X. 2017, 6, 1-6. 


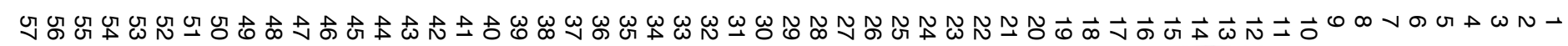

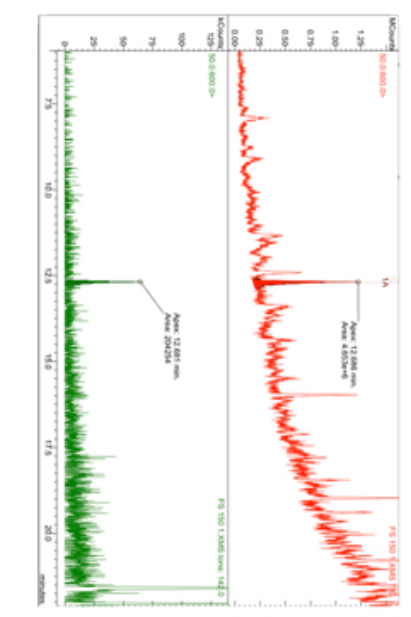

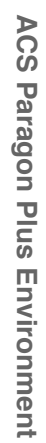
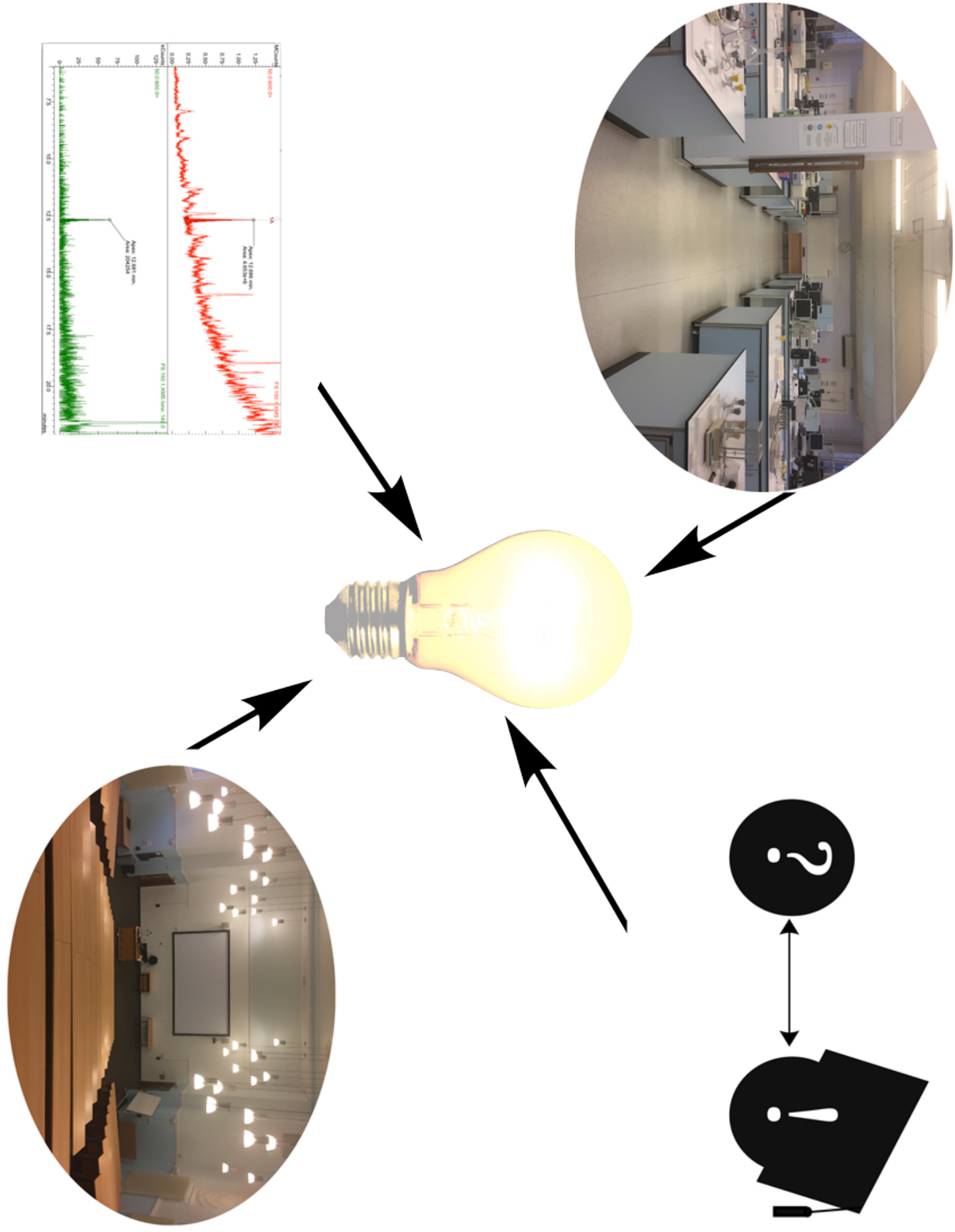

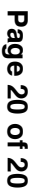

